\title{
Homicídio seguido de suicídio: relato de caso
}

\author{
Homicide followed by suicide: case report \\ Helena Dias de Castro Bins ${ }^{1}$, Cíntia Döler², Paulo Oscar Teitelbaum ${ }^{3}$
}

${ }^{1}$ Médica psiquiatra forense, Instituto Psiquiátrico Forense Dr. Maurício Cardoso de Porto Alegre (IPFMC), Porto Alegre, RS. ${ }^{2}$ Médica psiquiatra forense, IPFMC. ${ }^{3}$ Médico psiquiatra forense. Mestrando, Psiquiatria Forense, Universidad Nacional de La Plata (UNLP), La Plata, Argentina. Supervisor pericial, IPFMC.

\section{Resumo}

Objetivo: Examinar o fenômeno clínico de homicídio seguido de suicídio (HS) a partir de um caso no qual o desfecho de suicídio não ocorreu por motivos alheios à vontade e às ações do sujeito.

Descrição do caso: Trata-se do caso de um homem que matou sua namorada por ciúmes, por ocasião do término do relacionamento entre ambos, tentando, a seguir, o suicídio. No presente artigo, é dada especial ênfase aos aspectos forenses do caso, avaliado para fins de determinação de responsabilidade penal e acompanhado no Instituto Psiquiátrico Forense Dr. Maurício Cardoso, Porto Alegre (RS).

Comentários: Ressalta-se que, ao se modificar o desfecho de um caso típico de HS, por não ter se consumado o suicídio do homicida, dois aspectos assumem relevância: as consequências legais a serem enfrentadas pelo sujeito e o manejo do impacto psíquico no sobrevivente. Do ponto de vista da prevenção, o conhecimento do fenômeno HS e dos fatores descritos como associados a ele justificaria uma constante atenção ao tema por parte dos profissionais de saúde mental. O presente relato foi autorizado pelo paciente através de termo de consentimento livre e esclarecido.

Descritores: Violência, psiquiatria forense, homicídio, suicídio, transtorno depressivo.

\begin{abstract}
Objective: The clinical phenomenon of homicide followed by suicide (HS) is examined through a case in which suicide was avoided despite the individual's will and actions.

Case description: A man killed his girlfriend at the end of the relationship because of jealousy. After that, he attempted suicide. Special emphasis is given to the forensic aspects of the case, which has been assessed to determinate the individual's criminal responsibility and has been followed up at the Forensic Psychiatric Institute Dr. Maurício Cardoso, in Porto Alegre, state of Rio Grande do Sul, Brazil.

Comments: When the outcome of a typical case of HS is modified and the suicide of the murderer is not accomplished, two aspects become important: the legal consequences to be faced by the murderer and the management of the psychological impact on the survivor. Regarding prevention, the knowledge of HS and its associated factors require constant attention by mental health professionals. This report was authorized by the patient by means of informed consent.

Keywords: Violence, forensic psychiatry, homicide, suicide, depressive disorder.
\end{abstract}

\section{Introdução}

A expressão homicídio-suicídio (HS) define um quadro de homicídio seguido pelo suicídio de seu perpetrador após um intervalo de tempo que varia entre algumas horas e 1 semana $^{1-6}$.

É possível distinguir cinco tipos de HS: por ciúme, marital relacionado a declínio da saúde, tipo filicídio-suicídio, tipo familicídio-suicídio e extrafamiliar?

É um fenômeno relativamente raro, situando-se na faixa de entre 0,2 a 0,3 eventos por 100 mil habitantes/ano ${ }^{1,6-12}$, mas de grande impacto, e estudos têm demonstrado que tais taxas se mantêm constantes nas mais variadas latitudes ${ }^{6,10,12}$. No Brasil, não foram localizados estudos sobre a ocorrência desse fenômeno com abrangência nacional; todavia, um estudo regional realizado em Porto Alegre (RS) ${ }^{13}$ revisou os casos locais de HS entre os anos de 1996 e 2004, tendo identificado 14 casos. Os resultados encontrados assemelharam-se ao panorama descrito na literatura internacional, sendo a grande maioria dos perpetradores composta por homens e, a das vítimas, por mulheres ${ }^{1,3,4,6-8,13-16}$. Os envolvidos eram

\section{Correspondência:}

Helena Dias de Castro Bins, Rua Carlos Huber, 800, CEP 91330-150, Bairro Três Figueiras, Porto Alegre, RS. Tel.: (51) 3387.8889,(51) 8401.3201. E-mail: helenabins@ gmail.com

Não há conflitos de interesse associados à publicação deste artigo. 
familiares, pessoas que se conheciam, ou que mantinham relacionamentos amorosos $3,4,6,8,10,17$.

A revisão da literatura aponta para os seguintes fatores de risco para a perpetração de HS: ser homem, jovem (geralmente mais velho do que a mulher), apresentar história de depressão ${ }^{1,4,6,18}$, manter relações amorosas conflituosas, ter acesso a armas de fogo e existir uma ameaça (real ou fantasiada) ou consumação de separação. Por outro lado, o uso de álcool não é fator específico de risco e, apesar de alguns autores afirmarem sua importância, esta é menos relevante se comparada à incidência do álcool nos casos de homicídio sem suicídio ${ }^{1,3}$

Do ponto de vista da psiquiatria forense, é importante destacar o risco de "patologizar" os casos de HS, uma vez que a maior parte ocorre em um contexto de relacionamentos amorosos conflituosos nos quais, apesar de o fator precipitante da violência ser, usualmente, o ciúme, este quase nunca apresenta características delirantes, não configurando um quadro psicótico ${ }^{19}$.

No momento atual, não existe um sistema classificatório adequadamente validado para o fenômeno que nos ocupa. Marzuk et al. ${ }^{2}$ propuseram um sistema de classificação categorial com base no tipo de relacionamento mantido entre o assassino e a vítima e na natureza dos motivos alegados para o crime.

O tipo mais comum é o HS por ciúme, correspondendo a $50-75 \%$ de todos os casos nos EUA $^{4,5,7}$. O agressor é tipicamente um homem entre 18 e 60 anos de idade, em geral alguns anos mais velho do que sua parceira. O conflito principal desenvolve-se em torno de uma rejeição da vítima a uma tentativa de reaproximação do parceiro, ciente ou com fortes suspeitas de infidelidade por parte da sua namorada, esposa ou amante $^{1,3,6}$. O HS por ciúme é predominantemente um crime masculino ( $90 \%$ dos casos), já que, nos episódios em que a mulher mata seu marido ou amante, o crime é, normalmente, um gesto de autodefesa ante agressões repetidas, raramente sendo seguido de suicídio ${ }^{7,15}$. Esses quadros costumam corresponder ao diagnóstico de síndrome da mulher espancada, uma das possíveis apresentações do transtorno de estresse pós-traumático ${ }^{20}$

Destaca-se que a literatura trata de casos de homicídio seguido de tentativa de suicídio (H-TS) da mesma forma que aborda os de HS por considerar que a dinâmica e o perfil dos envolvidos são semelhantes, sendo a intenção suicida clara e manifesta, "não se consumando por uma questão de sorte" 10 .

Alguns autores, inclusive, ressaltam as vantagens do estudo de casos de H-TS sobre os de HS, pois nestes os homicidas também morreram e não estão mais disponíveis para entrevista ou para lançar luz no porquê de seus atos. De outra parte, em casos como o estudado aqui, nos que os perpetradores não tiveram sucesso nas tentativas de suicidar-se, eles estavam disponíveis para serem investigados, aumentando a possibilidade de novas compreensões sobre suas motivações e circunstâncias psíquicas ${ }^{10,12}$.

\section{Descrição do caso}

Paciente de sexo masculino, 35 anos (34 na época do fato), branco, separado, ensino fundamental completo, motorista profissional. Não apresenta antecedentes mórbidos pessoais dignos de nota e nega história familiar de alcoolismo, uso de drogas ilícitas, suicídio, doença mental ou internações psiquiátricas.

Começou a trabalhar aos 14 anos, mantendo até o início do seu quadro psiquiátrico, aos 31 anos, bom desempenho no trabalho. Sobre relacionamentos com mulheres, informa ter tido apenas uma namorada na adolescência, que rompeu o namoro por ter se mudado para outra cidade. Sua segunda namorada foi sua ex-esposa.

A doença atual teve início aproximadamente 4 anos antes do fato (H-TS), quando sua esposa decidiu-se pela separação após um casamento de 11 anos, mudando-se de cidade e levando em sua companhia o único filho do casal. O paciente não encontra uma motivação clara para a decisão da esposa de separar-se, referindo que ela "queria se mudar de cidade e eu não quis; dizia que estava cansada de viver comigo" (sic).

Com a separação, teve início um quadro depressivo clinicamente sintomático: sentia-se permanentemente triste, apático, inapetente, desanimado e sem conseguir comparecer ao trabalho com regularidade. Passava dias seguidos sem conseguir levantar da cama ou realizar cuidados básicos de higiene. Não via perspectivas para sua vida. Começou a ouvir vozes mandando que se matasse (alucinações auditivas de comando). Realizou, então, sua primeira tentativa de suicídio (TS), ingerindo um litro de veneno para ratos e necessitando cuidados médicos de emergência.

Nesta ocasião (31 anos), ocorreu sua primeira busca por tratamento psiquiátrico, o qual abandonou após poucos meses por "não sentir nenhuma melhora" (sic), apesar de afirmar o desaparecimento das vozes que o incitavam a matar-se. Este tratamento constou de uma abordagem psiquiátrica clínica, em nível ambulatorial, com a utilização de antidepressivos em doses subplenas. Nos 2 anos seguintes, refere não ter se sentido "livre da tristeza" (sic) em qualquer momento, realizando, nesse período, mais duas TS, provocando acidentes frontais quando estava ao volante de ônibus da empresa onde trabalhava com a intenção consciente de morrer. É digno de nota que, nas duas oportunidades, o ônibus não conduzia passageiros, pois o paciente não tinha intenção de machucar outras pessoas (sic). Não há referência a sintomas psicóticos (alterações da sensopercepção ou do pensamento) posteriores aos que se seguiram à primeira TS. $\mathrm{O}$ paciente nega internações psiquiátricas.

Nos 11 meses anteriores ao delito, o paciente havia estabelecido um relacionamento com uma mulher alguns anos mais jovem, que, nos últimos tempos, vinha manifestando dúvidas sobre o desejo de manter o namoro.

Na noite do crime, o paciente avistou-a em um bar, na companhia de outro homem. Sentindo-se muito perturbado, não se deixou ver e voltou para casa. Algumas horas mais tarde, foi procurado pela namorada, que manifestou-lhe a intenção de dar fim à relação de ambos. Neste momento, o pa- 
ciente perdeu o controle (sic) e estrangulou a vítima. Depois, mantendo a noção de que havia matado a namorada, tentou ocultar o cadáver para não ser descoberto, abandonando-o em local ermo próximo, retornando então para sua residência.

Pela manhã, após algumas horas, tentou suicídio por enforcamento, sendo encontrado por acaso, já desacordado, por um familiar. Permaneceu internado por uma semana devido ao risco clínico de morte. Após a alta clínica, foi encaminhado ao Instituto Psiquiátrico Forense Dr. Maurício Cardoso (IPFMC), Porto Alegre (RS), por determinação judicial, para tratamento e realização de perícia para avaliação de responsabilidade penal, denunciado pelos delitos de homicídio e ocultação de cadáver.

Por ocasião da internação no IPFMC, em um quadro francamente psicótico, o paciente alega não se lembrar de detalhes do crime e dos motivos que o levaram a esconder o corpo: "Matei-a e depois tentei me suicidar. Vou tentar de novo, eu a amava e agora ela está me esperando" (sic).

Ao exame, o paciente apresentava-se fisicamente debilitado, com sulcos contínuos e profundos no pescoço (marcas características de enforcamento). Estava lúcido, hipovigil e hipotenaz. Na sensopercepção, apresentava alucinações auditivas (vozes de comando dizendo-lhe que devia matarse). Estava orientado quanto a espaço e tempo. A memória apresentava amnésia lacunar para o delito e eventos relacionados. O pensamento era de produção mágica, com o conteúdo marcado por ideias de ruína, desesperança e desvalia, além de ideação suicida (de caráter intrusivo e obsessivo) e plano suicida (planejava enforcar-se para se encontrar com a namorada morta); o curso de pensamento era lentificado. Estava bradilálico e a inteligência foi inferida clinicamente como de nível médio. $\mathrm{O}$ humor estava francamente deprimido, e a conduta, apática e hipoativa. Os exames laboratorial e neurológico não apresentaram alterações significativas.

A hipótese diagnóstica, na internação, foi de episódio depressivo grave com sintomas psicóticos (CID-10: F32.3).

Do ponto de vista pericial, em relação à responsabilidade penal, pode-se concluir pela imputabilidade do paciente no momento em que cometeu os delitos (homicídio e ocultação de cadáver), registrando, também, a presença de um quadro diagnosticado como depressão grave com sintomas psicóticos (CID-10: F32.3) quando da realização da perícia, portanto, superveniente ao cometimento dos delitos.

\section{Discussão}

O paciente apresenta diversos dos fatores de risco estabelecidos na literatura como favorecedores de casos de HS (ou H-TS), entre os quais destacamos: faixa etária compatível com maior probabilidade de manifestação de transtorno de humor; história de quadro depressivo importante com duração de mais de 1 ano, iniciado após perda afetiva real; tentativas anteriores de suicídio; ameaça recente de nova perda afetiva configurada pelo encontro da namorada na companhia de outro homem e concretizada pela comunicação sobre o rompimento do relacionamento.

Os delitos foram cometidos de forma impulsiva no contexto de um quadro depressivo; porém, a perícia de avaliação da responsabilidade penal não foi capaz de localizar sinais ou sintomas de que tal quadro fosse de dimensão psicótica. A manutenção das capacidades cognitivas e volitivas, bem como do teste de realidade, podem se configurar pela preocupação do paciente em proteger-se escondendo o cadáver da vítima após o homicídio, voltando, a seguir, para sua casa.

O quadro psicótico instalou-se algumas horas após o homicídio, quando alterações do pensamento e da sensopercepção (já descritas) levaram-no a TS, que não se consumou por motivos alheios à sua vontade.

Os autores entendem que, no caso deste paciente, o fator predominante no desencadeamento da conduta homicida não é a perda da parceira sexual, ou o fato de ver a namorada com outro homem, o que provocou no paciente uma reação de retraimento (sentiu-se triste e foi para casa), mas se relaciona com uma nova ruptura de relacionamento, pois somente quando, mais tarde, ela o procurou para concretizar o término da relação, reagiu impulsivamente ao abandono e matou-a ${ }^{18,19}$.

Apesar da gravidade do quadro no momento da perícia, o examinando foi considerado imputável no momento do crime, levando em conta que o quadro diagnosticado como episódio depressivo grave com sintomas psicóticos sobreveio ao cometimento dos delitos (homicídio e ocultação de cadáver). Do ponto de vista psiquiátrico-forense, a abolição ou atenuação da responsabilidade penal requer que seja estabelecida com clareza a existência de nexo causal entre a condição psicopatológica e a conduta tipificada como crime, o que não se verificou no caso. Na visão dos peritos, ao cometer os delitos, o paciente mantinha intactas suas capacidades cognitivas (a noção de que matar é crime) e volitivas (a capacidade de dirigir sua conduta de acordo com a noção de que matar é crime). A tentativa de ocultação do cadáver é um forte indicativo de manutenção de tais capacidades. Somente após o delito, sobreveio o quadro psicótico descrito.

Conclui-se que, apesar de a literatura apontar uma prevalência de HS relativamente pequena se comparada à ocorrência de homicídio e suicídio separadamente, é importante que os profissionais de saúde mental estejam atentos a situações onde se façam presentes fatores de risco associados ao desfecho HS, no sentido de promover ações terapêuticas de caráter preventivo.

O impacto dos casos de HS para as famílias envolvidas, para o próprio agressor e mesmo para os profissionais de saúde mental justifica uma maior atenção ao tema, devendo abranger não somente os casos consumados de suicídio, mas principalmente aqueles nos quais o agressor sobrevive após a tentativa de suicídio. Nesta situação, o desfecho acarreta consequências legais, resultando em cumprimento de longa pena privativa de liberdade ou medida de segurança, comprometendo de forma grave e indelével, tanto o homicida sobrevivente quanto sua família. 


\section{Referências}

1. Bossarte RM, Simon TR, Barker L. Characteristics of homicide followed by suicide incidents in multiple states, 2003-2004. Inj Prev. 2006;12 Suppl 2:33-8.

2. Marzuk PM, Tardiff K, Hirsch CS. The epidemiology of murder-suicide. JAMA. 1992;267:3179-83

3. Saleva O, Putkonen H, Kiviruusu O, Lönnqvist J. Homicide-suicide - an event hard to prevent and separate from homicide or suicide. Forensic Sci Int. 2007;166:204-8.

4. Chan CY, Beh SL, Broadhurst RG. Homicide-suicide in Hong Kong, 1989-1998. Forensic Sci Int. 2003;137:165-71.

5. Mathews S, Abrahams N, Jewkes R, Martin LJ, Lombard C, Vetten L. Intimate femicide-suicide in South Africa: a cross-sectional study. Bull World Health Organ. 2008; $86: 552-8$.

6. Saint-Martin P, Bouyssy M, O'Byrne P. Homicide-suicide in Tours, France (20002005) - description of 10 cases and a review of the literature. J Forensic Leg Med. 2008;15:104-9.

7. Mendlowicz MV, Fontenelle LF, Mecler K. Transtornos do humor e violência. In: Taborda JGV, Chalub M, Abdalla-Filho E. Psiquiatria forense. Porto Alegre: Artmed Editora; 2004. p. 243-56.

8. Connolly J. Murder-suicide. Crisis. 2007;28(3):111-2

9. Comstock RD, Mallonee S, Kruger E, Rayno K, Vance A, Jordan F. Epidemiology of homicide-suicide events, Oklahoma, 1994-2001. Am J Forensic Med Pathol. 2005;26:229-35.

10. Brett A. Murder-parasuicide - a case series in Western Australia. Psychiatry Psychol Law. 2002;9(1):96-9.
11. Coid J. The epidemiology of abnormal homicide and murder followed by suicide. Psychol Med. 1983;13:855-60.

12. Gupta BD, Singh OG. A unique trend of murder-suicide in the Jamnagar region of Gujarat, India (a retrospective study of 5 years). J Forensic Leg Med. 2008;15:250-5.

13. Werlang BS, Sá SD. Homicídio seguido de suicídio na cidade de Porto Alegre. Estud Psicol. 2007;24(2):181-9.

14. Patel N, Webb K, White D, Barker L, Crosby A, DeBerry M, et al. Homicides and suicides - National Violent Death Reporting System, United States, 2003-2004. MMWR. 2006;55(26):721-4.

15. Sá SD, Werlang BS. Homicídio seguido de suicídio: revisão da literatura. Arq Bras Psiquiatr Neurol Med Leg. 2005;99(4):42-8

16. Logan J, Hill HA, Black ML, Crosby AE, Karch DL, Barnes JD, et al. Characteristics of perpetrators in homicide-followed-by-suicide incidents: National Violent Death Reporting System - 17 US States, 2003-2005. Am J Epidemiol. 2008;168:1056-64.

17. Banks L, Crandall C, Sklar D, Bauer M. A comparison of intimate partner homicide to intimate partner homicide-suicide: one hundred and twenty-four new Mexico cases. Viol Against Women. 2008;14:1065.

18. Rosembaum M. The role of depression in couples involved in murder-suicide and homicide. Am J Psychiatry. 1990;147:1036-9.

19. Daly M, Wilson M. Homicide. New York: Aldine de Gruyter; 1988

20. Cardoso RG. Defesa baseada na síndrome da mulher espancada. Rev Multijuris. 2006;1(2):46-51. 